\title{
The Potential of Teacher Development with Geometer's Sketchpad
}

\author{
Gerrit Stols \\ Andile Mji \\ Dirk Wessels \\ University of Pretoria \\ Tshwane University of Technology \\ University of Stellenbosch \\ mjia@tut.ac.za \\ dcjwessels@gmail.com
}

In this paper we document the advantages of utilising technology to enhance teachers' instructional activities. In particular we showcase the potential and impact that the use of Geometer's Sketchpad may have on the teaching and learning of geometry at school. A series of five, two-hour teacher development workshops in which Geometer's Sketchpad was used were attended by 12 Grade 11 and 12 teachers. The findings revealed that teachers had a better understanding of the same geometry that they initially disliked. This finding was supported by a quantitative analysis which showed a positive change in the understanding of and beliefs about geometry from when the teachers started to the end of the workshops.

Research has shown that teachers with different kinds of understanding of a particular topic tend to teach it differently (Kinach, 2002). Researchers have argued that a teacher's level of understanding plays a major role in influencing the knowledge that learners construct (e.g. Doyle, 1988; Koehler \& Grouws, 1991). In fact, others (e.g. Brown \& Borko, 1992) have in concurrence pointed to the importance of teachers having strong content knowledge. Such content knowledge is said to give teachers the "confidence and resources to engage children at more challenging levels and undertake more adventurous learning tasks” (Taylor \& Vinjevold, 1999, p. 161). One method that is available and which may be helpful in improving teachers' conceptual understanding is technology. An important aspect of technology is that when used appropriately it reinforces higher cognitive skill development and complex thinking skills such as problem solving, reasoning, decision making, as well as scientific inquiry (Moersch, 1999).

With respect to mathematics teaching in particular, researchers have agued that technology has the potential for enhancing instruction (Connell, 1998; Roschelle, Pea, Hoadley, Gordin, \& Means, 2000). In fact, Dede (2000) indicated that technology can be used to strengthen student learning and enhance pedagogy. Further, it has been pointed out that appropriate usage of technology tools may enhance teachers' conceptual development (Sanders 1998).
Such enhanced conceptual development should be useful to the students tutored by these teachers. To this effect, it has been argued that teachers who were comfortable with technology and possessed solid basic skills are more likely to use constructivist teaching practices (Rakes, Fields, \& Cox, 2006). Related to this, these authors have also asserted:

Given the current emphasis on producing students with high levels of thinking skills, any tools that can encourage the use of constructivist classroom practices and encourage the development of thinking skills in students should be considered important for all teachers and students. (p. 422)

Recently there have also been calls for the use of technology to be incorporated into teacher education. Researchers in support of the calls have even provided categories of different approaches taken by teacher trainers to bring technology into their programs (cf. Garofalo, Drier, Harper, Timmerman \& Shockey, 2000).

The importance of technology in the teaching and learning of mathematics was also identified and stressed by the National Council of Teachers of Mathematics (NCTM) as one of the six principles of high quality mathematics education. The principle, known as the 'technology principle' states that technology is "...essential in teaching and learning 
mathematics; it influences the mathematics that is taught and enhances students' learning” (NCTM 2000, p. 24).

In South Africa, the need to incorporate technology in the classroom has been identified too. Initiatives to incorporate technology into the teaching and learning context are exemplified by the support the national Department of Education gave to the formal launching of SchoolNet SA in 1997 (cf. Riordon, 2007). Also, computer companies such as Sahara Systems have been involved in spearheading initiatives to furnish computer labs within public schools in Gauteng as well as the Free State, with ICT infrastructure and digital equipment (Network Times, 2007). The importance of technology notwithstanding, it is worth noting that mathematics teachers, and not technological tools, are the key change agents needed to bring about reform in mathematics teaching. With this is in mind, we introduced Geometer's Sketchpad to inservice teachers of mathematics.

Geometer's Sketchpad was originally designed for teaching geometry in secondary schools. It includes the classical ruler and compass constructions, as well as isometries. The program allows teachers and learners to work quickly through numerous examples (by dragging) and enables them to discover patterns, to explore and to test conjectures by constructing their own sketches.

Sketchpad 4 and later versions has a number of trigonometric and algebraic features, which enables teachers and learners to find relationships between symbolic and graphic representations. Geometer's Sketchpad is a powerful teaching and learning medium. In fact this programme has been reported to (a) enhance mathematics teaching; (b) help with conceptual development; (c) enrich visualisation of geometry; (d) lay a foundation for analysis and deductive proof; and (e) create opportunities for creative thinking (Sanders 1998). In this study, the use of the Geometer's Sketchpad was based on the theoretical basis advanced by Wong (1998), who argued that graphing software helps to (a) develop concepts and reinforce concepts; (b) rectify common errors; (c) check graphical solutions; (d) solve equations graphically; (e) test conjectures through problem posing; (f) become meta cognitive, to acquire information technology skills; and (g) enhance the motivation to learn. In introducing this particular programme we were conscious that it would not in itself improve the quality of education but it would help enhance the qualities identified when technology is introduced to teachers (Sanders, 1998; Wong, 1998). In fact, we particularly selected Geometer's Sketchpad on the knowledge that the use of computers in mathematics education can be harmful when used for drill and practice, but helpful when used for exploration (Wenglinsky, 1998). The main objective therefore was to examine the impact of workshops that introduced the dynamic geometry software to teachers. In particular, the study examined changes in teachers' knowledge of and beliefs about geometry when dynamic software is introduced in the teaching and learning of geometry.

\section{Method}

\section{Participants and procedure}

The participants were 15 teachers from previously disadvantaged schools in the Pretoria region. All were Grade 11 and 12 geometry teachers who taught mathematics in previously disadvantaged schools. Participation of these individuals was at the recommendation of the local Department of Education. Of the original 15 participants, 12 completed a series of five workshops. The three who dropped out indicated that they were not computer literate and requested to be excused. Initially, a pilot study was conducted with one teacher who was not part of the final 12 participants. The aim of this pilot investigation was primarily to determine whether we could (a) monitor the change and growth in the teacher's conceptual development and understanding of mathematics following the use of Geometer's Sketchpad; (b) develop and refine training materials (teachers' worksheets and notes) depending on feedback from the teacher; and to establish (c) logistical issues such as the duration and nature of a full basic course using Geometer's Sketchpad with teachers. The pilot run for all intents and purposes proved to be extremely worthwhile. For instance, the participating teacher was complementary of the software in terms of its ease of use as well as in helping her understand geometrical theory much better. She actually indicated "I think this is a good program because you can show learners how theorems can be proved by measurement ... easily dragging and changing angles..." The pilot was also useful because the teacher provided valuable feedback on the prepared manual. This allowed for some activities to be modified while one activity was removed completely because she felt it was difficult for the targeted grade levels as well as time consuming. 


\section{Material}

A manual prepared for the workshops contained basic operational instructions for using Geometer's Sketchpad, as well as problems for teachers to solve. In developing mathematics activities and materials, we followed the guidelines set by Garofalo et al. (2000) for appropriate uses of technology in mathematics teaching:

- introduce technology in context

- address worthwhile mathematics with appropriate pedagogy

- take advantage of technology

- connect mathematics topics

- incorporate multiple representations

The manual covered most of the grade 11 and 12 geometry curricula, as well as graphs of the trigonometric functions, straight lines and parabolas. In essence the workshop manual integrated the development of computer skills (Geometer's Sketchpad) and geometric discovery.

Typically, the starting point involved a discussion about how to conduct an investigation using Geometer's Sketchpad. For example, the teachers had to draw a cyclic quadrilateral and determine some of its features. An advantage of an activity such as this is that it allowed teachers to have a hands-on experience of the operational functions of Geometer's Sketchpad. Also, it allowed them to create the geometric diagrams, as well as determine the veracity of geometric proofs regarding the diagrams (the cyclic quadrilateral, in this case).

\section{Data collection and analysis}

Data were drawn from a series of five two-hour workshops that were conducted by the first author over a period of three months. A mixed methods design was used to collect both qualitative and quantitative data. Qualitative data was obtained through reflective journals that teachers kept and this information was augmented by one-on-one interviews conducted by the first author. Here, over the duration of the workshops, teachers were encouraged to keep a reflective journal of their experiences. These reflective journals provided the researchers with documentation on a continuous cycle of enquiry. We also asked teachers to provide information about the availability of computers in general, their usage of these and where they used these. Further information was obtained by asking teachers to complete a questionnaire that was intended to evaluate their beliefs about geometry as well as their feelings about what was done at each workshop. A typical question asked, for example was There is a view which suggests that geometry is the most difficult section in school mathematics, how do you feel about this? At the end of three months a summative evaluation questionnaire was once again administered. Here, teachers were again asked about their views about geometry and the activities they had engaged in. A typical question in this instance was Think back to when you started the workshops, how do you feel about geometry now? In addition one teacher was video-recorded during each session while working. The recordings were in order to capture all activities the teacher engaged in and to allow for a rerun of the tapes which allowed for the analysis to be as accurate as possible.

Quantitative data on the other hand, was obtained from paper and pencil tests involving a pre-test and a post-test. The pre-test was written before any intervention was carried out, that is before the introduction of teachers to Geometer's Sketchpad. For the post-test, the same test was used after the intervention (see Appendix A). The aim of the two tests was to establish whether there would be changes in teachers' knowledge with respect to Grade 11 and Grade 12 mathematics topics. We measured the change as a function of the difference between the teachers' scores in the two tests. Differences were established by computing a paired-samples t-test where, if there was no statistically significant difference it would be concluded that there were no changes in teachers' knowledge about the covered mathematics topics.

\section{Results \\ Qualitative analysis}

With respect to the availability and usage of computers, teachers had differing self reports, as shown in the frequency distribution in Table 1 . The table reveals that a majority of the teachers had computers at school, for some these were functional and that they utilised word processors for their school work. Only one teacher reported that he had an email address with internet access at home.

Table 1: Computer availability and usage

\begin{tabular}{|l|c|c|}
\hline Computer Activity & N & $\mathbf{\%}$ \\
\hline Computers at school & 11 & 92 \\
Functional computer laboratory at school & 9 & 75 \\
Computers at home & 8 & 67 \\
Internet at home & 1 & 8 \\
Have an e-mail address & 2 & 16 \\
Use word processors for school work & 7 & 58 \\
\hline
\end{tabular}

About their feelings with respect to teaching geometry, 10 of the 12 participants reported that 
they struggled to teach this section of mathematics. Statements such as: teaching geometry is a nightmare; teaching geometry is difficult; teaching geometry is hell ... were advanced by seven of the teachers. Also, seven teachers blamed their learners. In this instance the teachers indicated: learners have negative attitudes; learners find it difficult; learners must learn theorems and practice geometry ...

In the summative evaluation at the completion of the workshops however, attitudes changed completely and were more positive. Some of the feedback revealed: I will try to open afternoon classes in the computer laboratory for my pupils so that I can give them more attention to improve their geometry; learners are more enthusiastic about mathematics. They work more problems than usual; learners will be very positive in doing geometry unlike the situation that we are having at our schools where they are negative ...

In fact all the teachers indicated that the workshops helped them to better understood geometry and felt more confident in teaching it. The teachers identified the fifth workshop as the most useful. In this particular workshop they had to design their own riders and solve them. This exercise by their own admission, was very meaningful in their teaching. Feedback here included: I had a problem before but now I think I will approach it (geometry) with confidence; After this workshop I think I have gained confidence in teaching geometry; When I came here I had a very negative attitude as learners did not really understand geometry, but now I am positive that $I$ will also change the learners' attitude toward geometry. A disconcerting outcome was the view from 9 of the 12 teachers that: you need Geometer's Sketchpad to teach geometry successfully.

An analysis of the video recordings as well as the interviews revealed a better conceptual understanding of the problems teachers were dealing with. In fact, the recordings showed teachers solving advanced problems which on their own admission they never thought they would ever be able to tackle. The teachers were able to interpret and apply geometric principles and used these to reach generalised conclusions. For example, one teacher was very excited when he independently found the solution of the sum of the interior angles of a 100-gon. He constructed a triangle, a quadrilateral and a pentagon. He then constructed a point inside each polygon and connected this newly constructed point to all the vertices of the polygon. The teacher then concluded that the triangle contained three triangles, the quadrilateral four triangles, and the pentagon five triangles. What we found exciting was the fact that he also understood that he should subtract the newly created revolution $\left(360^{\circ}\right)$ in each case to calculate the sum of the interior angles of the polygons. His conclusion was that the sum of the interior angles of a 100 -gon is "...100 triangles minus one revolution that is, 17640 ...” We certainly cannot paint a picture of the feelings this particular teacher displayed after solving this problem.

\section{Quantitative analysis}

Table 2 shows the means, the standard deviations and the percentage improvement of scores from the paper-and-pencil test.

The table reveals that there was a positive improvement from the pre-test to the post-test in all the four questions with the percentage improvement ranging between $10,8 \%$ and $30,8 \%$. Paired-samples t-test indicated that the differences among the means were statistically significant $(p<0,05)$ for Questions 1,3 and 4 while the difference was not statistically significant for Question 2. It was then concluded that there were changes in teachers' knowledge about the covered mathematics topics.

Table 2: Statistics from the paper-and-pencil test

\begin{tabular}{|c|c|c|c|c|c|}
\hline \multirow[t]{2}{*}{ Test question } & \multicolumn{2}{|c|}{ Mean (SD) } & \multirow[t]{2}{*}{ \% Improvement } & \multirow[t]{2}{*}{$t$} & \multirow[t]{2}{*}{$p$} \\
\hline & Pre-test & Post-test & & & \\
\hline Q1 (6) & $3,77(2,3)$ & $5,62(0,6)$ & 30,8 & $2,98 *$ & 0,011 \\
\hline Q2 (6) & $4,14(2,2)$ & $4,79(2,0)$ & 10,8 & 1,26 & 0,229 \\
\hline Q3 (9) & $4,46(4,1)$ & $6,23(4,1)$ & 12,7 & $2,83^{*}$ & 0,014 \\
\hline Q4 (10) & $4,46(4,1)$ & $6,23(4,1)$ & 17,7 & $2,21 *$ & 0,024 \\
\hline
\end{tabular}

\section{Discussion}

The results reported here provide a good illustration of the potential and impact that the use of Geometer's Sketchpad may have on the teaching and learning of geometry and may be mathematics at school. By their own admission, teachers indicated that they had a better understanding of the geometry that they initially disliked. They also indicated more enthusiasm for mathematics by their learners. To this effect they reported that their learners tackled more problems than it previously had been the case. These 
qualitative findings were supported by the quantitative analysis. In this analysis, an improvement of more than $10 \%$ was reported. More than that, changes in teachers' knowledge were found to be statistically significant.

The findings of this study are consistent with arguments that technology provides an optimal medium for the application of constructivist principles to learning (Murphy, 1997). To be more specific, the best improvement from pre- to post-test was question 1 . This question was about the transformation of a trigonometric function:

Draw the graph of $y=\frac{1}{2} \cos x+1$ on the interval $\left[-180^{\circ} ; 180^{\circ}\right]$.

The teachers were not allowed to use Sketchpad during the pre- and post-tests. The statistically significant improvement of $30,8 \%(p<0,05)$ therefore shows a growth in understanding and also indicates that Sketchpad is particularly useful in developing an understanding of the transformation of functions. Although there was a $10,8 \%(\mathrm{p}<0,05)$ improvement in question 2 , it was not statistically significant. The question was to determine the equation of an altitude of a triangle (see Appendix A). Although the use of Geometer's Sketchpad during the workshops helped the teachers to know what an altitude is, four of the teachers could still not determine the equation of the altitude. Teachers' average for question 3 in the pre-test was $78,6 \%$ and this indicates that the teachers had a high level of knowledge about the circle relationships before the intervention. However, the intervention still made a difference: Table 1 shows a statistically significant improvement of $12,7 \%(\mathrm{p}<0,05)$ from the pre to post-test in question 3 . The question concerned the relationship between the angles in a circle. The software is therefore useful for discovering relationships between angles and helped the teachers to make conjectures and to use them to answer simple questions. The purpose of question 4 was to determine if the teachers can use their knowledge to solve more complicated geometry problems. Question 4 measures their ability to use these relationships to do a proof. The mean in the pre-test for question 3 was $78,6 \%$ and for question 4 is $44,6 \%$, a difference of $17,7 \%$. The implication is that, although the teachers knew the angle relationships of a circle, they were not able to use the knowledge effectively to solve more advanced geometric problems. In the post-test after the intervention, the average for question 3 was
$91,2 \%$ and for question 4 is $62,3 \%$, a difference of $28,9 \%$. Although the teachers' ability to solve more advanced problems increased, the gap between knowing and applying mathematical principles also increased. This is an indication that Geometer's Sketchpad is a tool for exploration but cannot be used (in the way that we used it in this study) to narrow the gap between knowledge about relationships and application of the relationships in doing proofs.

An important aspect of this study was the fact that the approach of integrating the development of computer skills with geometric discovery proved successful. This is important because researchers (e.g. Becker \& Anderson, 2000; Ertmer, 1999) have shown that the attitudes and beliefs of teachers about the role of technology in the curriculum can influence how and when they use as well as integrate computers into their teaching.

Although Sketchpad was found to promote teachers' understanding of geometry, a major pitfall was the fact that teachers believed it was the best way to teach geometry effectively. As has been pointed out previously, teachers need to understand that technology is essential if it enhances what they know because otherwise it may also be misused and therefore be of no value to their teaching. Perhaps follow-up workshops in future should include discussions of how to discover and explore geometry without the use of computers. The encouraging findings, not withstanding a limitation of this study, relates to the availability and cost of Geometer's Sketchpad at schools. Almost all the teachers did not have this programme in their schools. Those who had the Geometer's Sketchpad identified its cost as an inhibiting factor because they had used their own funds to buy it. Perhaps this is an issue that education authorities should look at if a better understanding of geometry in our schools is to be envisaged. This is important because professional development activities coordinated say by the Department of Education could then go to a higher level. In this regard, researchers have shown that if teachers are active in professional development working side by side with their colleagues then they tend to effectively use technology with their students (Frank, Zhao, \& Borman, 2004). This study demonstrated that there is merit in teacher development with Geometer's Sketchpad because it will positively change the teaching and learning of geometry in our schools. 


\section{Acknowledgements}

This paper was made possible by a grant from the NRF. The statements made and views expressed are solely those of the authors.

\section{References}

Becker, H. J., \& Anderson, R. E. (2000). Subject and teacher objectives for computer-using classes by school socio-economic status. Irvine, CA and Minneapolis, MN: Center for Research on Information Technology and Organizations, University of California, Irvine, and University of Minnesota.

Brown, C. A., \& Borko, H. (1992). Becoming a mathematics teacher. In D. A. Grouws, (Ed.), Handbook of research on mathematics teaching and learning: A Project of the National Council of Teachers of Mathematics (pp. 209-237). New York: Macmillan.

Connell, M. (1998). Technology in constructivist mathematics classrooms. Journal of Computers in Mathematics and Science Teaching, 17(4), 311-338.

Dede, C. (2000). Emerging influences of information technology on school curriculum. Journal of Curriculum Studies, 32(2), 281-303.

Doyle, W. (1988) Work in mathematics classes: The context of students' thinking during instruction. Educational Psychologist, 23(2), 167-180.

Ertmer, P. A. (1999). Addressing first- and secondorder barriers to change: Strategies for technology integration. Educational Technology Research and Development, 47(4), 47-61.

Frank, K. A., Zhao, Y., \& Borman, K. (2004). Social capital and the diffusion of innovations within organizations: Application to the implementation of computer technology in schools. Sociology of Education, 77(2), 148-171.

Garofalo, J., Drier, H., Harper, S., Timmerman, M. A., \& Shockey, T. (2000). Promoting appropriate uses of technology in mathematics teacher preparation. Contemporary Issues in Technology and Teacher Education, 1(1), 66-88.

Kinach, B. M. (2002). A cognitive strategy for developing pedagogical content knowledge in the secondary mathematics methods course: Towards a model of effective practice. Teaching and Teacher Education, 18, 51-57.
Koehler, M. S., \& Grouws, D. A. (1991). Mathematics teaching practices and their effects. In D. A. Grouws, (Ed.), Handbook of research on mathematics teaching and learning: A Project of the National Council of Teachers of Mathematics (pp. 115-126). New York: Macmillan.

Moersch, C. (1999). Assessing current technology use in the classroom: A key to efficient staff development and technology planning. Learning and Leading with Technology, 26(8), 40-49.

Murphy, E. (1997). Constructivism: From philosophy to practice. Retrieved 10 April 2007 from www.stemnet.nf.ca/ elmurphy/emurphy/cle.html

National Council of Teachers of Mathematics [NCTM] (2000). Principles and standards for school mathematics. Retrieved 12 May 2007 from http://standards.nctm.org

Network Times (2007). Sahara at the forefront of ICT skills development and PC literacy. Retrieved 15 May 2007 from http://networktimes.co.za/news.aspx?pklNewsId= 23645\&pklCategoryID=305

Rakes, G. C., Fields, V. S., \& Cox, K. E. (2006). The influence of teachers' technology use on instructional practices. Journal of Research on Technology in Education, 38(4), 409-424.

Riordon, S. (2007). SchoolNet South Africa: Accessing a world of learning. Retrieved 15 May 2007 from www.scienceinafrica.co.za/school.htm

Roschelle, J., Pea, R., Hoadley, C., Gordin, D., \& Means, B. (2000). Changing how and what children learn in school with computer-based technologies. The Future of Children, 10(2), 76-101.

Sanders, C. V. (1998). Geometric constructions: Visualizing and understanding geometry. Mathematics Teacher, 91(7), 554-556.

Taylor, N., \& Vinjevold, P. (Eds.) (1999). Getting learning right. Report of the President's Education Initiative Research Project. Johannesburg: The Joint Education Trust.

Wenglinsky, H. (1998). Does It Compute? The relationship between educational technology and student achievement in mathematics, Princeton: Educational Testing Service. Retrieved 10 August 2007 from ftp://ftp.ets.org/pub/res/technolog.pdf

Wong, K. Y. (1998). Graphing software: computers for mathematics instruction (CMI) project. Retrieved 24 August 2007 from www.sun.ac.za/mathed/software/graphmat.pdf 


\section{Appendix A}

Question 1: Draw the graph of $y=\frac{1}{2} \cos x+1$ on the interval $\left[-180^{\circ} ; 180^{\circ}\right]$.

Question 2: $\quad A(-2 ; 8), B(-4 ;-2)$ and $C(2 ; 6)$ are the vertices of $\triangle \mathrm{ABC}$ and $\mathrm{M}$ is the midpoint of $\mathrm{BC}$. MS $\perp \mathrm{AB}$.

Calculate the equation of the line SM

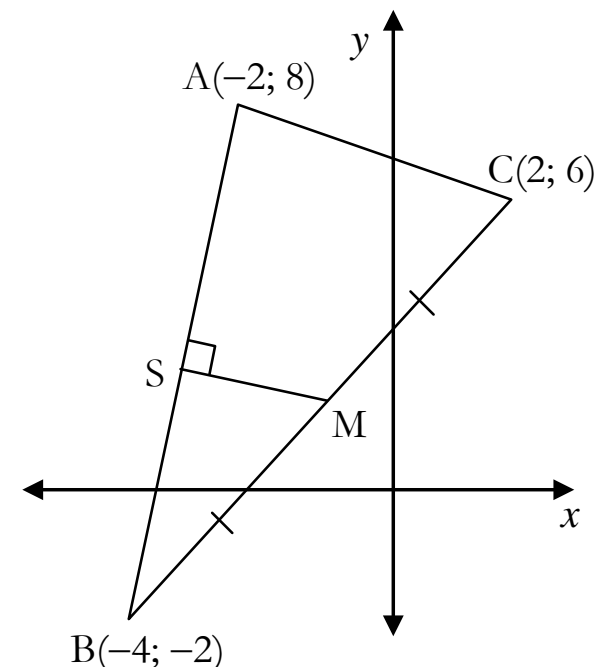

Question 3: Determine the unknowns if $\mathrm{O}$ is the centre of the circle:

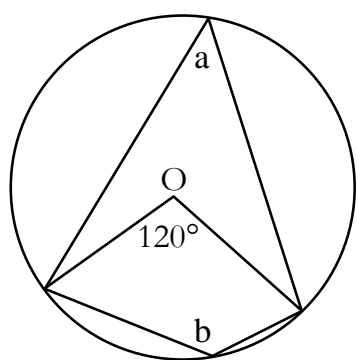

$\mathrm{a}=$

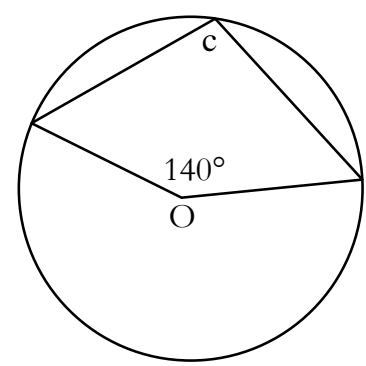

$\mathrm{c}=\ldots \ldots \ldots$

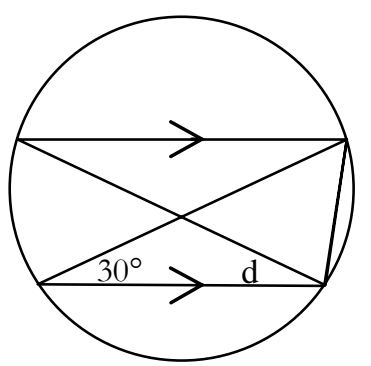

$\mathrm{d}=\ldots \ldots \ldots$

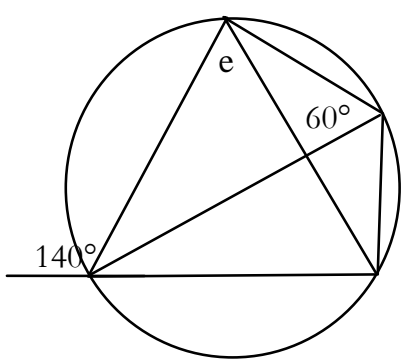

$\mathrm{e}=$

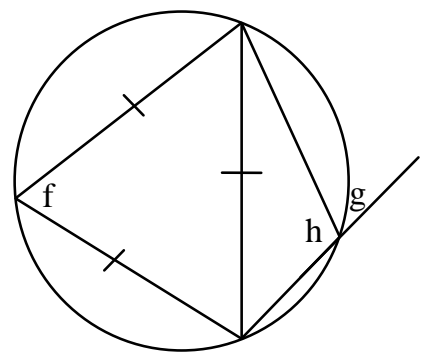

$\mathrm{h}=$

$\mathrm{f}=$

$\mathrm{g}=$

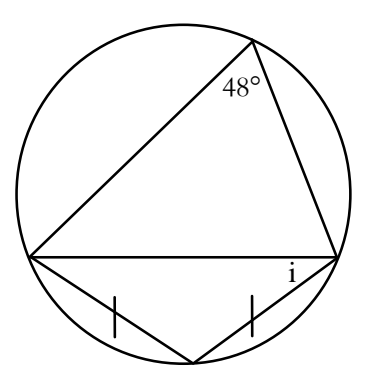

$\mathrm{i}=$

Question 4: Calculate the values of $x$ and $y$ : (Give a full explanation with reasons.)

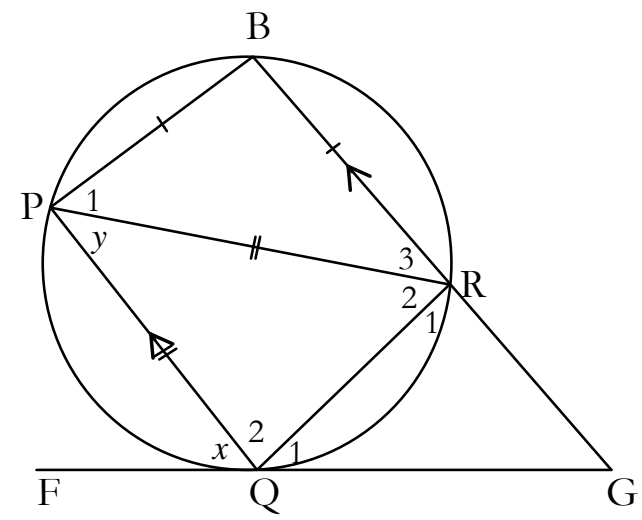

